\title{
Medio ambiente y el nuevo Estatuto de Autonomía de Andalucía ${ }^{1}$. Una visión preliminar
}

\author{
Jesús Jordano Fraga \\ Profesor Titular de Derecho Administrativo \\ Universidad de Sevilla
}

\begin{abstract}
SUMARIO: I. INTRODUCCIÓN. II. EL MEDIO AMBIENTE EN EL ESTATUTO DE AUTONOMÍA (NOVEDADES DESTACABLES): A) La introducción del medio ambiente entre los derechos/deberes estatutarios (arts. 28/36 EA) y de la tecnología de los principios rectores en el nivel estatutario (arts. 37-38 EA). B) La redefinición y modernización de las competencias en materia de medio ambiente. C). La introducción del TÍTULO VII "Medio ambiente", artículos 195-206 III. A MODO DE CONCLUSIÓN.
\end{abstract}

\section{INTRODUCCIÓN}

Han quedado atrás los tiempos en que el medio ambiente tenía una acogida tímida e indirecta en el derecho originario articulador de una comunidad. Hoy los tratados, las constituciones y los estatutos incluyen de forma amplia entre su articulado el medio ambiente. Es un lugar común, un signo de los tiempos y poderoso indicio de la transformación del Estado Social y democrático de Derecho hacia el Estado ambiental ${ }^{2}$. El Estatuto de Autonomía de Andalucía no se separa de esta línea progresiva sostenible. Desde el punto de vista normativo en ello ha influido poderosamente el constitucionalismo

\footnotetext{
${ }^{1}$ Estudio realizado en el marco del proyecto de investigación SEJ 2004-01046/JURI "régimen jurídico de los recursos naturales" del Ministerio de Educación y Ciencia.

${ }^{2}$ LETTERA, Lo Stato ambientale, Giuffré editore, Milano 1990 y Lo Stato ambientale e le generazioni future, "Rivista Giuridica dell’Ambiente", núm.2, junio 1992, pp. 235-255. En España, MONTORO CHINER El estado ambiental de derecho. Bases constitucionales, en El Derecho administrativo en el umbral del siglo XX. Homenaje al Profesor MARTÍN MATEO, Tomo III, Tirant lo Blanch, Valencia 2000, pp. 3437-3465.
} 
reciente, el derecho originario de la Unión Europea y los movimientos de reforma estatutaria desarrollados en España, especialmente, el de Cataluña.

En el nuevo Estatuto de Andalucía, el medio ambiente y el desarrollo sostenible lo impregnan todo. Y ello desde el principio (como en el Tratado CEE) situándose al medio ambiente entre los objetivos básicos de la Comunidad Autónoma integrado en el macro concepto de calidad de vida.

Artículo 10. Objetivos básicos de la Comunidad Autónoma.

3. Para todo ello, la Comunidad Autónoma, en defensa del interés general, ejercerá sus poderes con los siguientes objetivos básicos:

7.. La mejora de la calidad de vida de los andaluces y andaluzas, mediante la protección de la naturaleza y del medio ambiente, la adecuada gestión del agua y la solidaridad interterritorial en su uso y distribución, junto con el desarrollo de los equipamientos sociales, educativos, culturales y sanitarios,

La inspiración hemos de encontrarla en el art. 12, apartados, 5 y 6 del anterior Estatuto de Autonomía que, señalaban respectivamente como objetivos básicos de la Comunidad Autónoma.

$5^{\circ}$ El fomento de la calidad de vida del pueblo andaluz, mediante la protección de la naturaleza y del medio ambiente, y el desarrollo de los equipamientos sociales, con especial atención al medio rural.

$6^{\circ}$ La protección y realce del paisaje y del patrimonio artístico de Andalucía.

En su momento fue destacado su significado por PÉREZ MORENO ${ }^{3}$ : el crecimiento económico propugnado por nuestro Estatuto se deseaba alcanzar manteniendo un concepto cualitativo de calidad de vida que obliga a la protección de la naturaleza y del medio ambiente. Y, para PÉREZ MORENO, debía resaltarse el valor jurídico de estos objetivos "en cuanto, que se convierten en criterio o medida de la legitimidad de las normas y actos de los poderes regionales ${ }^{4}$.

La comparación de ambos textos permite comprobar que las modificaciones son de detalle, pues la desaparición de la mención al paisaje hoy se in-

\footnotetext{
${ }^{3}$ VV.AA, Comentarios al Estatuto de Autonomía, Instituto García Oviedo, Ediciones del Instituto García Oviedo núm. 50, Universidad de Sevilla, Sevilla 1981, pp. 71-72.

${ }^{4}$ Ibidem.
} 
cluye, como comprobaremos de inmediato, en la regulación del derecho (art. 28 , apartados 1 y 2 EA) y del principio rector (art. 37, 1 apartado 20).

En el nuevo Estatuto existe una amplia acogida de postulado ambiental y una adaptación a la realidad del siglo XXI en términos de estructura competencial. De otro lado, si la inicial presencia en el primigenio Estatuto permitía un reforzamiento de las posibilidades de control, hoy este control se ha tecnificado expandiendo técnicas jurídico-constitucionales al nivel Estatutario en los términos que vamos a examinar a continuación. Hemos subtitulado este estudio bajo la rúbrica "una visión preliminar". La reciénte promulgación de Estatuto mediante la Ley Orgánica 2/2007 de 19 de marzo ${ }^{5}$, de Reforma del Estatuto de Autonomía para Andalucía permite esta reflexión fresca -con las ventajas y los inconvenientes- que ello conlleva. Es evidente que han transcurrir algunos años para que sea posible un comentario certero y riguroso de las novedades introducidas por el movimiento de reforma estatutaria en España. En este sentido, y dado el apego al estatuto Catalán, la futura sentencia del Tribunal constitucional sobre el mismo, marcará decisivamente la interpretación conforme a la Constitución del Estatuto en aspectos esenciales objeto de nuestro comentario.

\section{EL MEDIO AMBIENTE EN EL ESTATUTO DE AUTONOMÍA (NOVEDADES DESTACABLES)}

La acogida del medio ambiente en el Estatuto de autonomía ha experimentado un verdadero big-bang. De una tímida presencia en los objetivos y competencias se ha evolucionado hacia un Estatuto impregnado de la idea ambiental con contenidos propios y específicos. Las novedades destacables en materia de Medio ambiente en el Estatuto de Andalucía pueden cifrarse en: A) La introducción del medio ambiente entre los derechos/deberes estatutarios arts. 28/36 EA y de la tecnología de los principios rectores en el nivel estatutario (arts. 37-38 EA); B) La redefinición y modernización de las competencias en materia de medio ambiente y, C) La introducción del TÍTULO VII, "Medio ambiente", artículos 195-206.

A) La introducción del medio ambiente entre los derechos/deberes estatutarios (arts. 28/36 EA) y de la tecnología de los principios rectores en el nivel estatutario (arts. 37-38 EA).

\footnotetext{
${ }^{5}$ B.O.E. 20 marzo 2007, núm. 68, p. 11871.
} 
En el marco de un verdadero proceso de constitucionalización de los estatutos -en tanto que carta de derechos ciudadanos-, el CAPÍTULO II, "Derechos y deberes" del nuevo Estatuto de autonomía de Andalucía reconoce el derecho a vivir en un medio ambiente equilibrado, sostenible y saludable. Veamos la fórmula para tal reconocimiento.

Artículo 28. Medio ambiente.

1. Todas las personas tienen derecho a vivir en un medio ambiente equilibrado, sostenible y saludable, así como a disfrutar de los recursos naturales, del entorno y el paisaje en condiciones de igualdad, debiendo hacer un uso responsable del mismo para evitar su deterioro y conservarlo para las generaciones futuras, de acuerdo con lo que determinen las leyes.

2. Se garantiza este derecho mediante una adecuada protección de la diversidad biológica y los procesos ecológicos, el patrimonio natural, el paisaje, el agua, el aire y los recursos naturales.

3. Todas las personas tienen derecho a acceder a la información medioambiental de que disponen los poderes públicos, en los términos que establezcan las leyes.

Artículo 36. Deberes.

1. En el ámbito de sus competencias, sin perjuicio de los deberes constitucionalmente establecidos, el Estatuto establece y la ley desarrollará la obligación de todas las personas de: a) Contribuir al sostenimiento del gasto público en función de sus ingresos. b) Conservar el medio ambiente.

2. Las empresas que desarrollen su actividad en Andalucía se ajustarán a los principios de respeto y conservación del medio ambiente establecidos en el Título VII. La Administración andaluza establecerá los correspondientes mecanismos de inspección y sanción.

Es fácil detectar la fuente de inspiración en el artículo 27 del nuevo Estatuto Catalán aprobado mediante la Ley Orgánica 6/2006, de 19 de julio, de reforma del Estatuto de Autonomía de Cataluña, que establece:

Artículo 27. Derechos y deberes con relación al medio ambiente.

1. Todas las personas tienen derecho a vivir en un medio equilibrado, sostenible y respetuoso hacia la salud, de acuerdo con los estándares y los niveles de protección que determinan las leyes. Tienen también derecho a gozar de los recursos naturales y del paisaje en condiciones de igualdad y tienen el deber de hacer un uso responsable de los mismos y evitar su despilfarro.

2. Todas las personas tienen derecho a la protección ante las distintas formas de contaminación, de acuerdo con los estándares y los niveles que se determinen por ley. Tienen también el deber de colaborar en la conservación del patrimonio na- 
tural y en las actuaciones que tiendan a eliminar las diferentes formas de contaminación, con el objetivo de su mantenimiento y conservación para las generaciones futuras.

3. Todas las personas tienen derecho a acceder a la información medioambiental de que disponen los poderes públicos. El derecho de información sólo puede ser limitado por motivos de orden público justificados, en los términos que establecen las leyes.

El nuevo Estatuto de Andalucía paralelamente establece el respeto del medio ambiente como principio rector:

Artículo 37. Principios rectores.

1. Los poderes de la Comunidad Autónoma orientarán sus políticas públicas a garantizar y asegurar el ejercicio de los derechos reconocidos en el Capítulo anterior y alcanzar los objetivos básicos establecidos en el artículo 10, mediante la aplicación efectiva de los siguientes principios rectores:

$20 .^{\circ}$ El respeto del medio ambiente, incluyendo el paisaje y los recursos naturales y garantizando la calidad del agua y del aire.

21. ${ }^{\circ}$ El impulso y desarrollo de las energías renovables, el ahorro y eficiencia energética.

22.․ El uso racional del suelo, adoptando cuantas medidas sean necesarias para evitar la especulación y promoviendo el acceso de los colectivos necesitados a viviendas protegidas.

Nuevamente la inspiración en cuanto a la consagración de principios rectores en el nivel estatutario es el Estatuto Catalán. Su artículo al establecer el principio rector 46 dispone:

Artículo 46. Medio ambiente, desarrollo sostenible y equilibrio territorial.

1. Los poderes públicos deben velar por la protección del medio ambiente mediante la adopción de políticas públicas basadas en el desarrollo sostenible y la solidaridad colectiva e intergeneracional.

2. Las políticas medioambientales deben dirigirse especialmente a la reducción de las distintas formas de contaminación, la fijación de estándares y de niveles mínimos de protección, la articulación de medidas correctivas del impacto ambiental, la utilización racional de los recursos naturales, la prevención y el control de la erosión y de las actividades que alteran el régimen atmosférico y climático, y el respeto a los principios de preservación del medio, la conservación de los recursos naturales, la responsabilidad, la fiscalidad ecológica y el reciclaje y la reutilización de los bienes y los productos.

3. Los poderes públicos deben hacer efectivas las condiciones para la preservación de la naturaleza y la biodiversidad, deben promover la integración de objetivos 
ambientales en las políticas sectoriales y deben establecer las condiciones que permitan a todas las personas el goce del patrimonio natural y paisajístico.

4. Los poderes públicos deben velar por la cohesión económica y territorial aplicando políticas que aseguren un tratamiento especial de las zonas de montaña, la protección del paisaje, la defensa del litoral, el fomento de las actividades agrarias, ganaderas y silvícolas y una distribución equilibrada al territorio de los distintos sectores productivos, los servicios de interés general y las redes de comunicación. 5. Los poderes públicos deben facilitar a los ciudadanos la información medioambiental y deben fomentar la educación en los valores de la preservación y de la mejora del medio ambiente como patrimonio común.

Obsérvese que la fórmula empleada por el Estatuto andaluz para el reconocimiento del derecho es equilibrado, sostenible y saludable frente adecuado del artículo 45 CE. También debe resaltarse la explicitación de la ley como parámetro del derecho ("de acuerdo con lo que determinen las leyes") y que no hay especificaciones del parámetro (como lo hubiera sido el establecimiento de un nivel de protección elevado o la inclusión bajo el ámbito de protección de las minorías especialmente susceptibles a determinados contaminantes). Se ha oscurecido la fórmula Catalana "ante las distintas formas de contaminación, de acuerdo con los estándares y los niveles que se determinen por ley" Probablemente la estructura del derecho a disfrutar de un medio ambiente adecuado reclama la inmediación normativa a imagen y semejanza de los tipos en blanco del derecho penal. Es precisa una determinación que requiere la labor del legislador. Aunque esto sea en parte cierto, ello sucede en el ámbito de otros derechos fundamentales clásicos (como el derecho de huelga, la libertad sindical, el derecho a la educación). La fórmula plantea el problema de si la ley actúa como límite para la responsabilidad $^{6}$, cosa que de momento la jurisprudencia del TS niega.

En sede de principio rector debe destacarse que de forma expresa se recoja el impulso y desarrollo de las energías renovables, el ahorro y eficiencia.

\footnotetext{
${ }^{6}$ Problema estudiado a la luz de la jurisprudencia alemana por MONTORO CHINER, María Jesús, Inactividad y Responsabilidad administrativa del Estado legislador por la "muerte de los bosques". La cuestión de la causalidad, en Gobierno y Administración en la Constitución, Vol. II, Dirección General de Servicio Jurídico del Estado, Instituto de Estudios Fiscales, Madrid 1988, pp. 1141-1173. Para un estudio especifico del mismo a la luz de la directiva europea que permite la exoneración de responsabilidad por la regulación de transposición de los Estados y su critica, véase nuestro trabajo La responsabilidad por daños ambientales en el Derecho de la Unión europea: análisis de la Directiva 2004/35/CE, de 21 de abril, sobre Reponsabilidad Medio Ambiental, en Estudios sobre la Directiva 2004/35/CE de Reponsabilidad por Daños ambientales y su Incidencia en el Ordenamiento Español, Monografía 7ª̣, Asociada a la Revista de Derecho Ambiental, Aranzadi, Elcano 2005,pp.13-49 y en Estudios de Derecho ambiental europeo, LETE, Pamplona 2005, pp. 62-104.
} 
Una vez más el postulado estatutario recoge del previo desarrollo legislativo. Como es sabido. Andalucía ha sido pionera en la aprobación de la Ley 2/2007, de $27 \mathrm{marzo}^{7}$, de Fomento de las energías renovables y del ahorro y eficiencia energética de Andalucía, Ley que bien merece llamarse la Ley PÉREZ MORENO, autor del Anteproyecto que ya está inspirando la legislación de otras Comunidades Autónomas.

En cuanto al valor de la protección del medio ambiente se ha seguido la estructura del art. 53.3 CE procediendo a la codificación de la jurisprudencia constitucional sobre los principios rectores. De esta forma los artículos 38 y 39 del nuevo Estatuto de Andalucía disponen:

Artículo 38. Vinculación de los poderes públicos y de los particulares. La prohibición de discriminación del artículo 14 y los derechos reconocidos en el Capítulo II vinculan a todos los poderes públicos andaluces y, dependiendo de la naturaleza de cada derecho, a los particulares, debiendo ser interpretados en el sentido más favorable a su plena efectividad. El Parlamento aprobará las correspondientes leyes de desarrollo, que respetarán, en todo caso, el contenido de los mismos establecido por el Estatuto, y determinarán las prestaciones y servicios vinculados, en su caso, al ejercicio de estos derechos.

Artículo 39. Protección jurisdiccional.

Los actos de los poderes públicos de la Comunidad que vulneren los derechos mencionados en el artículo anterior podrán ser objeto de recurso ante la jurisdicción correspondiente, de acuerdo con los procedimientos que establezcan las leyes procesales del Estado.

Artículo 40. Efectividad de los principios rectores.

1. El reconocimiento y protección de los principios rectores de las políticas públicas informará las normas legales y reglamentarias andaluzas, la práctica judicial y la actuación de los poderes públicos, y podrán ser alegados ante los jueces y tribunales de acuerdo con lo que dispongan las leyes que los desarrollen ${ }^{8}$.

2. Los poderes públicos de la Comunidad Autónoma de Andalucía adoptarán las medidas necesarias para el efectivo cumplimiento de estos principios, en su caso, mediante el impulso de la legislación pertinente, la garantía de una financiación suficiente y la eficacia y eficiencia de las actuaciones administrativas.

\footnotetext{
${ }^{7}$ BO. Junta de Andalucía 10 abril 2007, núm. 70, p. 7

${ }^{8}$ La inspiración es el art. 53.3 CE y en cuanto a su matización el 39, apartados 2 y 3 del Estatuto Catalán.
} 
Artículo 41. Defensa de los derechos.

Corresponde al Defensor o Defensora del Pueblo Andaluz velar por la defensa de los derechos enunciados en el presente Título, en los términos del artículo 128.

Las suspicacias que se pudieran plantear se eliminan mediante la introducción de una cláusula de protección de los derechos reconocidos en la CE y derecho internacional convencional. Veámosla:

Artículo 13. Alcance e interpretación de los derechos y principios.

Los derechos y principios del presente Título no supondrán una alteración del régimen de distribución de competencias, ni la creación de títulos competenciales nuevos o la modificación de los ya existentes. Ninguno de los derechos o principios contemplados en este Título puede ser interpretado, desarrollado o aplicado de modo que se limiten o reduzcan derechos o principios reconocidos por la Constitución o por los tratados y convenios internacionales ratificados por España ${ }^{9}$.

La nueva regulación posibilita, favorece y puede impulsar el control de eficacia de la Administración ambiental al establecer una cláusula de "efectividad de los principios rectores" en art. 40.2 respecto de los principios rectores equiparable al art. 9 CE. Los poderes públicos de la Comunidad Autónoma de Andalucía adoptarán las medidas necesarias para el efectivo cumplimiento de estos principios, en su caso, mediante el impulso de la legislación pertinente, la garantía de una financiación suficiente y la eficacia y eficiencia de las actuaciones administrativas. Hemos de destacar que tanto el Estatuto catalán como el andaluz han suprimido el "solo podrá ser alegados" del art. 53.3 CE. Entendemos que la fórmula es progresiva y hay que dotarla de mayor significación por vía interpretativa. Recordemos que ex art. 53.3 CE el Tribunal

\footnotetext{
${ }^{9}$ El precepto claramente se inspira en el art. 37 apartado 4 del Estatuto catalán. La fuente remota de inspiración es la Constitución europea: Conforme a su ARTÍCULO II-113, Nivel de protección, "Ninguna de las disposiciones de la presente Carta podrá interpretarse como limitativa o lesiva de los derechos humanos y libertades fundamentales reconocidos, en su respectivo ámbito de aplicación, por el Derecho de la Unión, el Derecho internacional y los convenios internacionales de los que son parte la Unión o todos los Estados miembros, y en particular el Convenio Europeo para la Protección de los Derechos Humanos y de las Libertades Fundamentales, así como por las constituciones de los Estados miembros”. Conforme al ARTÍCULO II-111 Ámbito de aplicación, apartado segundo "La presente Carta no amplía el ámbito de aplicación del Derecho de la Unión más allá de las competencias de la Unión, ni crea ninguna competencia o misión nuevas para la Unión, ni modifica las competencias y misiones definidas en las demás Partes de la Constitución”.
} 
supremo construye un derecho subjetivo a disfrutar del medio ambiente en la medida en que lo dispongan las leyes que lo desarrollen (STA de 6 de julio de 1983, Ar. 4018 (Sala 4a, Ponente SÁNCHEZ ANDRADE Y SAL; STS de 15 de abril de 1988, Ar 3074 (Sala 4a, Ponente MARTÍN MARTÍN); STS de 30 de abril de 1990, Ar 5620 (Sala 3a, sección quinta, Ponente GONZÁLEZ NAVARRO), o incluso ha extraído consecuencias directas; SSTS de 16 de abril de 1990, Ar. 3650 (Sala 3a, sección quinta, Ponente GONZÁLEZ NAVARRO) y de 7 de noviembre de 1990, Ar 8750 (Sala 3a, sección quinta, Ponente GONZÁLEZ NAVARRO), en la cual el T.S. ha considerado que el derecho a un medio ambiente adecuado implica el derecho a un medio ambiente acústicamente no contaminado ${ }^{10}$.

Entedemos que la consecuencia fundamental a extraer del nuevo texto estatutario es un plus respecto del diseño constitucional: la alegabilidad será en todo caso directa y no dependerá de que la ley establezca la posibilidad de alegación. Esta es la interpretación que ha hecho del art. 53.3 CE LÓPEZ MENUDO, al afirmar que la expresión "de acuerdo con lo que dispongan las leyes que los desarrollen" debe considerarse referida más al contenido sustantivo y no a los requisitos de legitimación ${ }^{11}$. Esta construcción la consagran al margen de toda duda los nuevos Estatutos de Andalucía y Cataluña.

\section{C) La redefinición y modernización de las competencias en materia de medio ambiente.}

Nuestro Estatuto en su Título I "Competencias de la Comunidad Autónoma”, artículos 14 y 15 , apartados 7 y 17 estableció el régimen de competencias autonómicas en materia de medio ambiente ${ }^{12}$. El artículo 14 EA estableció como competencias exclusivas la política territorial (ordenación del territorio y del li-

\footnotetext{
10 Sobre esta cuestión véanse DELGADO PIQUERAS, Régimen jurídico del Derecho constitucional al medio ambiente, "Revista Española de Derecho Constitucional", núm. 38, Mayo-agosto 1993, pp. 52-56. Posteriormente VELASCO CABALLERO, El medio ambiente en la Constitución: ¿Derecho Público subjetivo y/o principio rector?, "Revista Andaluza de Administración Pública”, núm. 19, Julio-agosto-septiembre 1994, págs. 77-114, y PINAR DIAZ, El derecho de la persona a disfrutar del medio ambiente en la jurisprudencia del Tribunal Supremo, "Actualidad Administrativa", núm. 18, semana 1-7 de mayo 1995, pp. 243-259.

${ }^{11}$ El derecho a la protección del medio ambiente, "Revista Española de Derecho Constitucional", septiembre-diciembre 1991, p.194.

12 Para un examen comparativo de las previsiones competenciales del anterior Estatuto en materia de medio ambiente con otros Estatutos, véase FAYA BARRIOS, Medio Ambiente, en VV.AA., Desarrollo de las competencias del Estatuto para Andalucía, Asociación de Letrados de la Junta de Andalucía,
} 
toral, urbanismo y vivienda); también una larga lista de títulos sobre recursos naturales (montes, aprovechamientos y servicios forestales, vías pecuarias -13 . 7 EA-, recursos hidráulicos y aprovechamientos hidráulicos -13.12 EA-; caza y pesca -13.18 EA-. Específicamente, en materia ambiental se señaló como competencia exclusiva los espacios naturales protegidos -13. 7 EA-. El artículo 15, apartado 1, 7 $7^{\mathrm{a}}$ estableció como competencia de la Comunidad Autónoma de Andalucía, en el marco de la regulación general del Estado, el desarrollo legislativo y la ejecución en materia de "Medio ambiente. Higiene de la contaminación biótica y abiótica”. Por último, el art. 17, apartado atribuyó a nuestra Comunidad la ejecución de la legislación del Estado sobre vertidos industriales y contaminantes en las aguas territoriales correspondientes al litoral andaluz. Como es sabido, el campo de la distribución de competencias en materia de medio ambiente ha sido especialmente complejo dando lugar a un conflicto cuya expresión máxima ha sido la Ley 8/1999, de octubre, del Espacio Natural de Doñana ${ }^{13}$.

Consejería de relaciones institucionales, Junta de Andalucía, Sevilla 2001, pp. 430-432. Sobre la distribución de competencias en materia de medio ambiente véanse los estudios de SEVILLA MERINO, Las competencias en materia de protección del medio ambiente, "R.E.V.L.", núm. 220, 1983, pp. 633-662; LARUMBE BIURRUM, Medio ambiente y Comunidad Autónoma, "R.V.A.P., núm. 8 1984, pp. 9-71; QUINTANA LÓPEZ, La distribución de competencias en la protección del medio ambiente. Referencia especial a las actividades mineras, "R.E.A.L.A." núms. 235-236, julio-diciembre 1987, pp. 533-572; SÁNCHEZ BLANCO, Distribución constitucional de competencias en materia de recursos naturales. (Aguas, montes, minas), en Estudios sobre la Constitución Española, Homenaje al Profesor García de ENTERRÍA, Tomo IV, Editorial Cívitas S.A., 1991, pp. 3567-3670; CUCHILLO FOIX, Las Competencias de la Generalitat de Catalunya en materia de medio ambiente, Libro Homenaje a VILLAR PALASÍ, editorial Cívitas, Madrid 1989, pp. 247-271; LÓPEZ MENUDO, Planteamiento constitucional del medio ambiente. Distribución de competencias Estado-Comunidades Autónomas en AA.VV, Protección Administrativa del medio ambiente, Consejo General del Poder Judicial, Madrid 1994, pp. 9-63; CANALS AMETLLER, La polémica jurisprudencia del Tribunal Constitucional en materia de espacios naturales protegidos: Competencias estatales versus competencias Autonómicas (Comentario a la STC 102/1995, de 26 de junio en relación con las SSTC 156/1995, de 26 de octubre y 163/1995, de 8 de noviembre), "R.A.P" núm. 142, enero-abril 1997, pp. 305-351; POMED SÁNCHEZ, La protección del medio ambiente como función estructural del Estado en el seno de la Unión Europea: entrecruzamientos competenciales, "R.E.D.A.”, núm. 98, abril-junio 1998, pp. 165-190; JORDANO FRAGA, Integración y desintegración en la construcción del federalismo ambiental: La STS 13/1998, de 22 de enero, o la razonable afirmación de competencias «ejecutivas» en «materia ambiental» fuera de las anormalidades, "REDA" núm. 101, enero-marzo 1999, pp. 103-115; BERNALDO DE QUIRÓS, Las competencias autonómicas sobre medio ambiente y su problemática en los Tribunales Superiores de Justicia en VV.AA., La protección Jurisdiccional del Medio ambiente, Cuadernos de Derecho Judicial XII, CGPJ, Madrid 2001, pp. 57-139; LÓPEZ MENUDO, Concepto constitucional de medio ambiente. El reparto competencial en VV, Reparto competencial en materia de medio ambiente. Control medioambiental de la Administración Pública, Estudios de Derecho judicial núm. 56, Consejo General del Poder Judicial, Madrid 2004, pp. 15-72; ALLI ARANGUREN, Distribución de las competencias ambientales entre el Estado, las Comunidades Autónomas y las Corporaciones Locales en VVAA, Diccionario de Derecho Ambiental, Iustel, Madrid 2006 pp. 522-531.

${ }^{13}$ Sobre esta cuestión véase nuestro estudio La Ley 8/1999, de octubre del Espacio Natural de Doñana: conflicto en el paraíso, "R.A.A.P." núm. 36, octubre-noviembre-diciembre 1999, pp. 261-287. 
Hemos de destacar dos aspectos: el nuevo Estatuto realiza una sistematización de las competencias ambientales en el art. 57 y atribuye a la Comunidad Autónoma la competencia sobre la cuenca hidrográfica del Guadalquivir en su artículo 51

Vamos con lo primero. Este es el contenido literal del art. 57 EA.

Artículo 57. Medio ambiente, espacios protegidos y sostenibilidad.

1. Corresponde a la Comunidad Autónoma la competencia exclusiva, sin perjuicio de lo dispuesto en el artículo 149.1.23. ${ }^{a}$ de la Constitución, en materia de:

a) Montes, explotaciones, aprovechamientos y servicios forestales.

b) Vías pecuarias.

c) Marismas y lagunas, y ecosistemas acuáticos.

d) Pastos y tratamiento especial de zonas de montaña.

e) Delimitación, regulación, ordenación y gestión integral de los espacios naturales protegidos, incluyendo los que afecten a las aguas marítimas de su jurisdicción, corredores biológicos, y hábitats en el territorio de Andalucía, así como la declaración de cualquier figura de protección y establecimiento de normas adicionales de protección ambiental.

f) Fauna y flora silvestres.

g) Prevención ambiental.

2. Corresponde a la Comunidad Autónoma la competencia exclusiva en materia de caza y pesca fluvial y lacustre que incluye en todo caso la planificación y la regulación de estas materias; y la regulación del régimen de intervención administrativa de la caza y la pesca, de la vigilancia y de los aprovechamientos cinegéticos y piscícolas.

3. Corresponde a la Comunidad Autónoma la competencia compartida en relación con el establecimiento y la regulación de los instrumentos de planificación ambiental y del procedimiento de tramitación y aprobación de estos instrumentos; el establecimiento y regulación de medidas de sostenibilidad e investigación ambientales; la regulación de los recursos naturales; la regulación sobre prevención en la producción de envases y embalajes; la regulación del ambiente atmosférico y de las distintas clases de contaminación del mismo; la regulación y la gestión de los vertidos efectuados en las aguas interiores de la Comunidad Autónoma, así como de los efectuados a las aguas superficiales y subterráneas que no transcurren por otra Comunidad Autónoma; la regulación de la prevención, el control, la corrección, la recuperación y la compensación de la contaminación del suelo y del subsuelo; la regulación sobre prevención y corrección de la generación de residuos con origen o destino en Andalucía; la regulación del régimen de autorizaciones y seguimiento de emisión de gases de efecto invernadero; el establecimiento y la regulación de medidas de fiscalidad ecológica; y la prevención, restauración y reparación de daños al medio ambiente, así como el correspondiente régimen sancionador. Asimismo, tiene competencias para el establecimiento de normas adicionales de protección. 
4. La Comisión bilateral Junta de Andalucía-Estado emite informe preceptivo sobre la declaración y delimitación de espacios naturales dotados de un régimen de protección estatal. Si el espacio está situado íntegramente en el territorio de Andalucía, la gestión corresponde a la Comunidad Autónoma.

5. Corresponde a la Comunidad Autónoma de Andalucía el establecimiento de un servicio meteorológico propio, el suministro de información meteorológica y climática, incluyendo el pronóstico, el control y el seguimiento de las situaciones meteorológicas de riesgo, así como la investigación en estos ámbitos y la elaboración de la cartografía climática ${ }^{14}$.

${ }^{14}$ La inspiración es clara en el art. 144 del Estatuto catalán, aun con diferencias: Artículo 144. Medio ambiente, espacios naturales y meteorología.

1. Corresponde a la Generalitat la competencia compartida en materia de medio ambiente y la competencia para el establecimiento de normas adicionales de protección.

Esta competencia compartida incluye en todo caso:

a) El establecimiento y la regulación de los instrumentos de planificación ambiental y del procedimiento de tramitación y aprobación de estos instrumentos.

b) El establecimiento y la regulación de medidas de sostenibilidad, fiscalidad e investigación ambientales.

c) La regulación de los recursos naturales, de la flora y la fauna, de la biodiversidad, del medio ambiente marino y acuático si no tienen por finalidad la preservación de los recursos pesqueros marítimos.

d) La regulación sobre prevención en la producción de envases y embalajes en todo su ciclo de vida, desde que se generan hasta que pasan a ser residuos.

e) La regulación sobre prevención y corrección de la generación de residuos con origen o destino en Cataluña y sobre su gestión y traslado y su disposición final.

f) La regulación de la prevención, el control, la corrección, la recuperación y la compensación de la contaminación de suelo y subsuelo.

g) La regulación y la gestión de los vertidos efectuados en las aguas interiores de Cataluña, así como de los efectuados en las aguas superficiales y subterráneas que no pasen por otra Comunidad Autónoma. En todo caso, dentro de su ámbito territorial, corresponde a la Generalitat la competencia ejecutiva sobre la intervención administrativa de los vertidos en las aguas superficiales y subterráneas.

h) La regulación del ambiente atmosférico y de las distintas clases de contaminación del mismo, la declaración de zonas de atmósfera contaminada y el establecimiento de otros instrumentos de control de la contaminación con independencia de la administración competente para autorizar la obra, la instalación o la actividad que la produzca.

i) La regulación del régimen de autorización y seguimiento de emisión de gases de efecto invernadero.

j) La promoción de las calificaciones relativas a productos, actividades, instalaciones, infraestructuras, procedimientos, procesos productivos o conductas respetuosas hacia el medio.

k) La prevención, restauración y reparación de daños al medio ambiente, así como el correspondiente régimen sancionador.

1) Las medidas de protección de las especies y el régimen sancionador.

2. Corresponde a la Generalitat, en materia de espacios naturales, la competencia exclusiva que, respetando lo dispuesto en el artículo 149.1.23 de la Constitución incluye, en todo caso, la 
Llama la atención la rúbrica del precepto "sostenibilidad". La sostenibilidad como título competencial nos parece un error. El desarrollo sostenible o la equidad intergeneracional es un principio del derecho ambiental. Este dislate sería equiparable a concebir la proporcionalidad como una materia competencial en sede de legislación procesal. El precepto que ahora comentamos viene a realizar la consagración estatutaria de la jurisprudencia constitucional sobre espacios naturales protegidos: son de gestión autonómica. (SSTC 102/95, de 26 de junio, 194/2004, de 10 de noviembre; 331/2005, de 15 de diciembre).

Debe resaltarse la letra e, del 57.1 EA cuando atribuye la competencia exclusiva sobre e) Delimitación, regulación, ordenación y gestión integral de los espacios naturales protegidos, incluyendo los que afecten a las aguas marítimas de su jurisdicción, corredores biológicos, y hábitats en el territorio de Andalucía, así como la declaración de cualquier figura de protección y establecimiento de normas adicionales de protección ambiental. Contrasta ello con el status quaestione de la jurisprudencia constitucional. Como sostuvo VALENCIA MARTÍN, al Estado le corresponden las principales funciones públicas previstas por el Derecho del Marr ${ }^{15}$ ) y la STC 38/2002, de 14 de febrero de 2002 ha reafirmado estas consideraciones ${ }^{16}$. El Estado impugnaba normativa autonó-

regulación y la declaración de las figuras de protección, delimitación, planificación y gestión de espacios naturales y de hábitats protegidos situados en Cataluña.

3. La Generalitat, en el caso de los espacios naturales que superan el territorio de Cataluña, debe promover los instrumentos de colaboración con otras Comunidades Autónomas para crear, delimitar, regular y gestionar dichos espacios.

4. La declaración y la delimitación de espacios naturales dotados de un régimen de protección estatal requiere el informe preceptivo de la Comisión Bilateral Generalitat-Estado. Si el espacio está situado íntegramente en el territorio de Cataluña, la gestión corresponde a la Generalitat.

5. Corresponde a la Generalitat el establecimiento de un servicio meteorológico propio, el suministro de información meteorológica y climática, incluyendo el pronóstico, el control y el seguimiento de las situaciones meteorológicas de riesgo, así como la investigación en estos ámbitos y la elaboración de la cartografía climática.

6. La Generalitat ejerce sus competencias mediante el Cuerpo de Agentes Rurales, competentes en la vigilancia, el control, la protección, la prevención integral y la colaboración en la gestión del medio ambiente. Los miembros de este cuerpo tienen la condición de agentes de la autoridad y ejercen funciones de policía administra administrativa especial y policía judicial, en los términos previstos en la ley.

${ }^{15}$ VALENCIA MARTÍN, ¿¿De Quien es el mar?, en El Derecho administrativo en el umbral del siglo XX. Homenaje al Profesor MARTÍN MATEO, Tomo III, Tirant lo Blanch, Valencia 2000, especialmente, pp. 3609-3616.

${ }^{16}$ Véase el excelente comentario de SÁNCHEZ LAMELAS, Dos cuestiones a propósito del título competencial "pesca marítima": el mar territorial como territorio autonómico y la delimitación de títulos competenciales concurrentes (Comentario a la STC 38/2002, de 14 de febrero de 2002, sobre el Parque Natural y la reserva Marina de Cabo de Gata-Níjar, "Tribunal Constitucional”, septiembre 2002, núm. 10, pp. 13-32. 
mica en relación con el Parque natural del Cabo Gata. La sentencia reduce la posibilidad de incidencia de las CC.AA sobre el mar territorial, incidencia que para nuestro Tribunal Constitucional será excepcional desde los espacios naturales protegidos (F.j. núm 6). SÁNCHEZ LAMELAS reconoce que el TC no reconoce expresamente que el mar territorial sea territorio de la Comunidad Autónoma, sino que mas bien el mar territorial forma parte del territorio autonómico a determinados efectos ${ }^{17}$. La expresión estatutaria por lo demás es desafortunada, porque aguas jurisdiccionales es un concepto de derecho internacional ligada a la soberanía de los Estados. Es esto un exceso estatutario. Y es más fiel a la jurisprudencia constitucional el art. 144.1 c) del Estatuto catalán al asignar la competencia c) La regulación de los recursos naturales, de la flora y la fauna, de la biodiversidad, del medio ambiente marino y acuático si no tienen por finalidad la preservación de los recursos pesqueros marítimos.

Obsérvese que el precepto andaluz realiza al igual que el art. 144 del Estatuto Catalán la introducción de una Comisión bilateral Junta de Andalucía-Estado que emite informe preceptivo sobre la declaración y delimitación de espacios naturales dotados de un régimen de protección estatal. Mas extraño es el párrafo segundo, del 57.4, por cuanto la jurisprudencia constitucional ha establecido que la extensión de un espacio natural mas allá de una Comunidad Autónoma, podrá dar lugar a los mecanismos de cooperación y coordinación, pero no altera la competencia para declarar y gestionar dichos espacios (STC 329/1993, f.j. núm. 4; 102/1995/f.j. 19), pero sobre todo la STC 306/2000, de 8 abril en relación con el PORN de parque Nacional de los Picos de Europa (si bien con importantes votos particulares). De hecho si se hubiera copiado literalmente el precepto del Estatuto Catalán, desaparecerían nuestras observaciones.

Allí el art. 144.3 establece "3. La Generalitat, en el caso de los espacios naturales que superan el territorio de Cataluña, debe promover los instrumentos de colaboración con otras Comunidades Autónomas para crear, delimitar, regular y gestionar dichos espacios".

Afirmado lo cual se entiende que se diga que 4. "La declaración y la delimitación de espacios naturales dotados de un régimen de protección estatal requiere el informe preceptivo de la Comisión Bilateral Generalitat-Estado. Si el espacio está situado integramente en el territorio de Cataluña, la gestión corresponde a la Generalitat".

\footnotetext{
17 Op. cit.pp. 17-18.
} 
Pero nuestro Estatuto omite esa precisión que recoge en este caso jurisprudencia constitucional. Su no plasmación en el Estatuto podrá ser criticada pero no tiene efecto alguno sobre las competencias.

Mas polémico ha sido sorprendentemente el nuevo art. $51 \mathrm{EA}$ que atribuye a la Comunidad Autónoma la competencia sobre la cuenca hidrográfica del Guadalquivir. Veamos el contenido del precepto:

Artículo 51. Cuenca Hidrográfica del Guadalquivir.

La Comunidad Autónoma de Andalucía ostenta competencias exclusivas sobre las aguas de la Cuenca del Guadalquivir que transcurren por su territorio y no afectan a otra Comunidad Autónoma, sin perjuicio de la planificación general del ciclo hidrológico, de las normas básicas sobre protección del medio ambiente, de las obras públicas hidráulicas de interés general y de lo previsto en el artículo 149.1.22. e de la Constitución.

En este caso hemos ido mas allá del estatuto Catalán que en su artículo 117 apartados 3,4 y 5 establece:

3. La Generalitat participa en la planificación hidrológica y en los órganos de gestión estatales de los recursos hídricos y de los aprovechamientos hidráulicos que pertenezcan a cuencas hidrográficas intercomunitarias. Corresponde a la Generalitat, dentro de su ámbito territorial, la competencia ejecutiva sobre:

a) La adopción de medidas adicionales de protección y saneamiento de los recursos hídricos y de los ecosistemas acuáticos.

b) La ejecución y la explotación de las obras de titularidad estatal si se establece mediante convenio.

c) Las facultades de policía del dominio público hidráulico atribuidas por la legislación estatal.

4. La Generalitat debe emitir un informe preceptivo para cualquier propuesta de trasvase de cuencas que implique la modificación de los recursos hídricos de su ámbito territorial.

5. La Generalitat participa en la planificación hidrológica de los recursos hídricos y de los aprovechamientos hidráulicos que pasen o finalicen en Cataluña provenientes de territorios de fuera del ámbito estatal español, de acuerdo con los mecanismos que establece el Título V y participará en su ejecución en los términos previstos por la legislación estatal.

El modelo catalán se basa en la participación no en la atribución de competencias exclusivas sobre una cuenca intercomunitaria.

El régimen de las competencias ambientales en nuevo estatuto de autonomía ha de completarse con las previsiones en materia de régimen local es- 
tablecidas en su artículo 92. "Régimen Local y medio ambiente". Este precepto atribuye a los Ayuntamientos competencias propias, en los términos que determinen las leyes: sobre abastecimiento de agua y tratamiento de aguas residuales, Ordenación y prestación de los siguientes servicios básicos: abastecimiento de agua y tratamiento de aguas residuales; recogida y tratamiento de residuos; limpieza viaria; Cooperación con otras Administraciones públicas para la promoción, defensa y protección del patrimonio histórico y artístico andaluz y cooperación con otras Administraciones públicas para la promoción, defensa y protección del medio ambiente y de la salud pública. Realizaremos en sede de conclusiones una valoración especial de la fórmula estatutaria de atribución de competencias.

\section{D). La introducción del TÍTULO VII "Medio ambiente", artículos 195-206.}

Destacamos en el Título II "Medio ambiente" el reforzamiento de la idea de desarrollo sostenible. Se trata de un conjunto de preceptos escasamente innovativos que abarcan la biodiversidad (art. 195), el uso sostenible de los recursos naturales (art. 196), la producción y el desarrollo sostenible (art. 197), residuos (art. 198), biotecnología (art. 199), incendios y desertificación (art. 200), contaminación (art. 201); desarrollo rural (art. 202); suelo (art. 203); recursos energéticos (art. 204); protección de los animales (art. 205); fiscalidad ecológica (art. 206).

Veamos el contenido literal de estos preceptos:

Artículo 195. Conservación de la biodiversidad. Los poderes públicos orientarán sus políticas a la protección del medio ambiente, la conservación de la biodiversidad, así como de la riqueza y variedad paisajística de Andalucía, para el disfrute de todos los andaluces y andaluzas y su legado a las generaciones venideras.

Artículo 196. Uso sostenible de los recursos naturales.

Los poderes públicos promoverán el desarrollo sostenible, el uso racional de los recursos naturales garantizando su capacidad de renovación, y la reducción de emisiones contaminantes a la atmósfera. Asimismo la Comunidad Autónoma promocionará la educación ambiental en el conjunto de la población.

Artículo 197. Producción y desarrollo sostenible.

1. En el marco de sus competencias, los poderes públicos de Andalucía orientarán sus políticas especialmente al desarrollo de la agricultura ecológica, el turismo sostenible, la protección del litoral y la red de espacios naturales protegidos, así como al fomento de una tecnología eficiente y limpia. Todos los sectores eco- 
nómicos vinculados al desarrollo sostenible cumplen un papel relevante en la defensa del medio ambiente.

2. Los poderes públicos de Andalucía impulsarán las políticas y dispondrán los instrumentos adecuados para hacer compatible la actividad económica con la óptima calidad ambiental, velando porque los sectores productivos protejan de forma efectiva el medio ambiente.

3. Los poderes públicos de Andalucía protegerán el ciclo integral del agua, y promoverán su uso sostenible, eficiente y responsable de acuerdo con el interés general.

Artículo 198. Residuos.

Corresponde a la Junta de Andalucía la planificación, supervisión y control de la gestión de los residuos urbanos e industriales. Se adoptarán los medios necesarios tanto para asegurar el cumplimiento de las normas como de las medidas para la reducción, reciclaje y reutilización de los residuos.

Artículo 199. Desarrollo tecnológico y biotecnológico.

Los poderes públicos de Andalucía fomentarán el desarrollo tecnológico y biotecnológico, así como la investigación y el empleo de recursos autóctonos orientados a procurar la mayor autonomía en materia agroalimentaria. El control de estas actividades corresponderá, en el marco de lo establecido en el artículo 149.1.15. ${ }^{\text {a }}$ de la Constitución, a la Junta de Andalucía, de acuerdo con los principios de precaución, seguridad y calidad alimentaria.

Artículo 200. Prevención de incendios forestales y lucha contra la desertificación.

Los poderes públicos pondrán en marcha mecanismos adecuados de lucha contra la desertificación, la deforestación y la erosión en Andalucía, realizarán planes de prevención de incendios forestales y extinción, así como la recuperación medioambiental de las zonas afectadas.

Artículo 201. Protección ante la contaminación.

1. Los poderes públicos de Andalucía promoverán políticas que mejoren la calidad de vida de la población mediante la reducción de las distintas formas de contaminación y la fijación de estándares y niveles de protección.

2. Dichas políticas se dirigirán, especialmente en el medio urbano, a la protección frente a la contaminación acústica, así como al control de la calidad del agua, del aire y del suelo.

Artículo 202. Desarrollo rural.

Los poderes públicos de Andalucía, con el objetivo conjunto de fijar la población del mundo rural y de mejorar su calidad de vida, promoverán estrategias integra- 
les de desarrollo rural, dirigidas a constituir las bases necesarias para propiciar un desarrollo sostenible.

Artículo 203. Uso eficiente del suelo y sistemas integrales de transporte.

1. Los poderes públicos de Andalucía velarán por un uso eficiente y sostenible del suelo, a fin de evitar la especulación urbanística y la configuración de áreas urbanizadas insostenibles.

2. La Comunidad Autónoma de Andalucía potenciará el desarrollo del transporte público colectivo, especialmente aquel más eficiente y menos contaminante.

Artículo 204. Utilización racional de los recursos energéticos.

Los poderes públicos de Andalucía pondrán en marcha estrategias dirigidas a evitar el cambio climático. Para ello potenciarán las energías renovables y limpias, y llevarán a cabo políticas que favorezcan la utilización sostenible de los recursos energéticos, la suficiencia energética y el ahorro.

Artículo 205. Protección de los animales.

Los poderes públicos velarán por la protección de los animales, en particular por aquellas especies en peligro de extinción. El Parlamento de Andalucía regulará por ley dicha protección.

Artículo 206. Incentivos y medidas fiscales.

1. Para la consecución de los objetivos establecidos en este Título, la Junta de Andalucía desarrollará políticas propias e incentivos a particulares adecuados a dicha finalidad.

2. Una ley del Parlamento de Andalucía regulará medidas de fiscalidad ecológica, preventivas, correctoras y compensatorias del daño ambiental en el marco de la Ley Orgánica a que se refiere el artículo 157.3 de la Constitución Española.

En este "todo lo que debería saber sobre legislación ambiental" hay preceptos descriptivos que rozan lo simbólico. Destacamos en este sentido, el artículo 197 EA "Todos los sectores económicos vinculados al desarrollo sostenible cumplen un papel relevante en la defensa del medio ambiente". Que recuerda el postulado desideratum constitucional de "los españoles serán justos y benéficos" de 1812 . 


\section{A MODO DE CONCLUSIÓN}

A la vista de lo expuesto, la primera crítica que debemos apuntar en relación con el nuevo Estatuto es el proceso de gestación desde la fase de borrador hasta su aprobación en referéndum. Muchos de los defectos apuntados hubieran sido fácilmente corregibles si se hubiera contado con el know-how ambiental marginado en el proceso de elaboración. El saber técnico restado de esta forma impregna de una sombra de adorno/florero a los preceptos ambientales del Estatuto. Y sobre todo de la sensación de una oportunidad perdida. Entre los aspectos discutibles debemos señalar los posibles excesos competenciales. De otro lado, se apuntala la excepcionalidad del carácter supletorio del Derecho estatal. Y se configura al Defensor de Andalucía (comisionado parlamentario autonómico como órgano de control de las entidades locales). En este último ámbito, señalamos una congelación del modo de estructuración de las relaciones entre Administración autonómica y Administración local ${ }^{18}$. La interiorización denunciada por ORTEGA tiene otro peligro nada desdeñable. La incoherencia frente a futuros modelos asentados en la legislación básica estatal. Valga un botón de muestra: El Estatuto de Andalucía establece una regulación sobre las competencias de los Municipios, Comarcas y Provincias en sus artículos 92, 96 y 97. De ella cabe destacar la previsión contenida en su artículo 92.2 que declara que "los Ayuntamientos tienen competencias propias" sobre una serie de materias "en los términos que determinen las leyes". Ha de notarse así, y repararse debidamente en ello, la importante

\footnotetext{
${ }^{18}$ En este sentido afirma Luis ORTEGA que si el modelo actual sufriese una interiorización autonómica, se haría en una situación funcional de espacios competenciales mínimos donde la voluntad autonómica de constituirse en la "administración única" limitaría una descentralización local. En su opinión, si algo tendría sentido, vista la experiencia de este período, sería introducir en una futura reforma constitucional, principios de ordenación y garantía del régimen local que permitan una activación más eficaz de los instrumentos de defensa de la autonomía local. El autor considera que el Estatuto de Cataluña sitúa a la Generalidad en una clara posición de predominio sobre los poderes locales que va mas allá del predominio ordinamental y los hace aparecer concebidos como entidades insertadas en la propia organización política de la Generalidad. En definitiva, piensa ORTEGA que la interiorización del régimen local por los Estatutos de Autonomía tiene su pleno sentido en la apertura del ordenamiento autonómico a la participación local en su ámbito de ejercicio de poderes públicos, pero ello no debe avocar a una reforma de la posición ordinamental del régimen local basado en la autonomía de su propio ordenamiento. Igualmente, afirma, las reformas estatutarias no deben ser pensadas como un vehículo para reinterpretar los títulos competenciales contenidos en la Constitución, pues ello implicaría situarse en la posición de legislador constituyente y en desconocer la posición del Tribunal Constitucional como supremo intérprete de la misma (Régimen local y Estatutos de Autonomía, "REALA" núm. 300-301, enero-agosto 2006, pp. 35-50).
} 
divergencia existente entre la regulación propuesta por el Anteproyecto de Ley básica estatal y la contenida en el Estatuto, en la medida en que el primero opta por una asignación directa de competencias a los Municipios en materias en las que el Estatuto establece una asignación de competencias conforme a lo dispuesto o en el marco de lo previsto en la legislación sectorial.

Una valoración sería incompleta sin estudiar las omisiones. Abordamos ahora el capítulo de carencias. Destacamos la falta de enunciación de principios del derecho ambiental o de su política legislativa (como el artículo 174 TCEE). Solo el Artículo 199. Desarrollo tecnológico y biotecnológico alude al principio de precaución. Tampoco el modelo del estatuto Catalán realiza esta tarea limitándose a recoger el importante principio de integración de la protección del medio ambiente en resto de las políticas en su artículo 46.3. Esta afirmación estatutaria de los principios hubiera sido un avance real. Son los principios los que fuerzan los avances en el ciclo de creación del Derecho.

El estatuto regula sin añadir nada materias consolidadas: el Estatuto actúa en este sentido como legge repetitae mínima. A pesar del aggiornamiento ambiental de Estatuto, existe una falta de cultura ambiental que se revela en la afirmación de los tópicos y en la ausencia de material innovativo. Nada se dice espresamente, por ejemplo, de la contaminación lumínica que impide la contemplación del firmamento y afecta las rutas de las aves migratorias. Y no comprendemos como ha podido desaprovecharse esta oportunidad de innovación pues frente a la idea de que ya está todo (o que va estarlo una vez se apruebe la GICA) queda mucho por hacer horizontalmente en el Derecho ambiental. Creemos que el Estatuto podría haber creado órganos estatuarios de participación real o haber reconocido directamente la acción popular. Estos si hubieran sido saltos trasformadores. Puestos a buscar algún sentido a esta operación de consagración estatutaria de principios ya recogidos en la legislación estatal y autonómica ambiental creemos que dicha consagración efectúa una congelación de la legislación ambiental al menos en su esquema mínimo impidiendo eventuales saltos atrás. Es decir estaríamos apuntalando la irreversibilidad de determinadas conquistas en la construcción del Estado Social y Ambiental de Derecho.

Mas discutible es la codificación de jurisprudencia constitucional en el nivel estatutario y su posible efecto congelador de la jurisprudencia constitucional. A lo lago de este estudio hemos visto como el desarrollo de grado de detalle en los preceptos que asignan competencias en los Estatutos de Andalucía y Catalán unas veces codifican la interpretación de la jurisprudencia constitucional y otras la redireccionan en un sentido autonomista. Esta operación des- 
tinada a blindar las competencias estatutarias está, a nuestro juicio, destinada al fracaso porque el máximo intérprete de la Constitución es Tribunal Constitucional y no el legislador orgánico.

Dicho todo lo anterior, el nuevo estatuto ya es nuestra norma jurídica fundamental como Comunidad Autónoma y cúspide keynesiana de nuestro derecho ambiental autonómico. Desde sus virtudes -también aquí destacadas-, contamos con una herramienta reforzada para la construcción de nuestro Estado Ambiental. El mayor reto es la traducción del potencial estatutario en derecho vivo. Este reto incumbe a todos (sociedad, operadores jurídicos, poderes públicos). El Tribunal Superior de Justicia de Andalucía debe ser uno de los líderes en esta tarea impulsando los elementos propios estatutarios en cuanto plus de garantías y mecanismos del control del ejercicio de potestades públicas desde el prisma ambiental. 